\title{
THE MYTH OF SUPERVENIENT MICROPHYSICALISM
}

\author{
Juan Diego Morales ${ }^{1}$
}

(Universidad de Cartagena)

So my aim is only to establish conditional claims of the form: even if certain facts are emergent vis-à-vis the microphysical realm, Physicalism can still be true.

Papineau, 2008: 132

\section{What physicalism is}

Let us begin with the idea that physicalism is the ontological theory which claims that the entities that constitute our world are physical entities, phenomena which the physical sciences must discover and articulate in their theories. ${ }^{2}$

Following the naturalistic trend of philosophy in recent times, contemporary philosophers have considered that physicalism is both an a posteriori and contingent thesis. Its a posteriori sense derives from the fact of being a position that tries to overcome the problems of its direct predeces-

1 jmoraleso1@unicartagena.edu.co. My thanks to Alejandro Rosas, Brian McLaughlin, Reinaldo Bernal, and Larry Shapiro, for helpful and clarifying comments on drafts of this paper.

2 Here I will use the general sense of "entity" and "phenomenon" for including both particulars (as objects, events, processes, and so on) and what many theorists take as universals (as properties, relations, and laws).

Philosophica, 48, Lisboa, 2016, pp. 47-61. 
sor, materialism. The latter was established as a metaphysical doctrine that attempted to specify the entities of our world in an a priori way, in terms of a specific set of features that supposedly defined the material; features such as conservation, deterministic and on contact interaction, impenetrability, inertia, and solidity. ${ }^{3}$ But this a priori specification proved to be wrong. It is now clear that if any of these conditions is necessary for something to count as material, then physics speaks of immaterial entities. ${ }^{4}$

But a posteriori physicalism faces not a minor problem, the so called Hempel's dilemma, which is based on an intuitive distinction between current physical science and complete or ideal future physical science. Hellman puts it in these terms:

[C]urrent physics is surely incomplete (even in its ontology) as well as inaccurate (in its laws). This poses a dilemma: either physicalist principles are based on current physics, in which case there is every reason to think they are false; or else they are not, in which case it is, at best, difficult to interpret them, since they are based on a 'physics' that does not exist - yet we lack any general criterion of 'physical object, property, or law' framed independently of physical theory. (Hellman, 1985: 609)

Physicalists respond to the problem in a very interesting and, I think, successful way; by arguing that their doctrine can be understood in terms of the complete physical science we can find and clearly recognize as a descendant of the current physical science. ${ }^{5}$ This is Papineau's formulation:

The idea here is to appeal to the categories represented by current Physics Departments, but to allow some wiggle room for future developments. So we might think of 'physical' as referring to all those categories that bear some resemblance to the categories recognized in contemporary Physics Departments. For example, 'physical' might be understood as equivalent to something like 'displaying mathematically simple and precise behaviour'. (Papineau, 2008: 130)

In this case, the physicalist affirms that the entities that constitute our world are those that that physical science postulates for its understanding and explanation. It is then clear that physicalism must satisfy some empirical and a posteriori conditions and, therefore, will be true only if the claims of the physical science upon which it rests come to account for our empirical world in a proper and all-sufficient form .

\footnotetext{
3 See, for example, Mettrie, 1748, and d'Holbach, 1770.

4 See Crane \& Mellor, 1990: 186, Stoljar, 2010: 10-11.

5 See, for example, Lewis, 1983: 361, Jackson, 1998: 8, and McLaughlin, 2007: note 3.
} 
Despite this, as Jessica Wilson says, "physicalists have not handed over all authority to physics to determine, a posteriori, what is physical." (2005: 428) The idea is that physicalism must also respond to some conceptual conditions imposed by the very notions of physical science and physical entity, which, as such, cannot be resolved in an a posteriori way by the physical science itself. Conditions applying both to the concept we now have of the physical, as to the one we can ever come to have. It is in this sense that if we recognize, for example, that physical science is essentially mathematical and quantitative, as Papineau suggests and it is intuitive to hold, then a complete future science intending to be recognized as physical will have to satisfy this condition. If the final science reaches a complete explanation of at least some facts of our world without having to resort to mathematical language, then physicalism will end up being false.

It is then clear that physicalism must also satisfy some a priori criteria. In fact, part of my argument is that many of the philosophical problems of the theorists working on the development of a correct characterization of what counts as physicalism arise precisely because of the lack of sufficient clarity of its conceptual and a priori conditions. In order to have an understanding of the concept of the physical and of the physicalist doctrine which should be built on this understanding, I will examine the way in which the contingent aspect of physicalism has been formulated, and the role that the concept of supervenience has played in such formulation.

\section{Physicalism as a contingent theory}

The notion of supervenience ${ }^{6}$ has been introduced and developed with the primary aim of accounting for two very relevant ideas which in principle are understood as compatible: the priority of physical phenomena within our world, and the irreducibility and difference of properties and phenomena that in principle we would not call physical, such as the mental, moral, political, and economic. It is precisely this idea that philosophers of morality as G.E. Moore and R.M. Hare, and philosophers of mind like Davidson, Fodor, and Putnam have in mind when affirm their naturalistic commitments.

But the concept of physical supervenience, which was introduced in order to articulate a non-reductive naturalistic approach, has in recent

\footnotetext{
In general terms, we can say that a set of properties A supervenes on another set of properties B, just in case there cannot be a difference in A without a difference in B. For an analysis of the concept see, for example, Kim, 1993, and McLaughlin \& Bennett, 2014.
} 
times served to account for the contingent aspect of physicalism. In order to achieve this goal, in one of the most quoted formulations of the physicalist doctrine, Jackson argues that the physicalist commitment should be interpreted as stating that "[a]ny world which is a minimal physical duplicate of our world is a duplicate simpliciter of our world" (1998: 12); where a minimal physical duplicate is what results from duplicating all and only all the physical facts; nothing more.

Most analytical philosophers, either physicalists or dualists, agree that this formulation captures the contingent aspect of physicalism, that is, its possibility of being true or false given only the facts of our world. And the reason that this formulation captures the contingency of physicalism is that, as Karen Bennett says, it "allows the possibility of worlds physically like ours, but with ghostly 'extras', and thus does not require that physicalism be necessarily true." (2008: 284$)^{7}$

The idea then is this: physicalism is the thesis that our world is completely physical; that the physical properties determine all its properties. But this statement does not say anything about other possible worlds different to ours; in particular, this statement is consistent with the fact that other possible worlds are made, completely or partially, by immaterial entities, Cartesian substances, or incorporeal souls. In fact, it is simply false, but completely coherent, to affirm that our world is constituted at least in part by immaterial entities, Cartesian substances, or incorporeal souls.

But here lies a deep problem that most contemporary theorists have not even suspected. The problem in a nutshell is that philosophers like Ryle, Wittgenstein, Davidson, Putnam, Burge, and Kim, among others, have built very important criticisms of the very intelligibility of the Cartesian dualism, and not merely of its empirical possibility. But if the contingency of physicalism is based on the possibility of our world being partially constituted by immaterial entities, Cartesian substances, or incorporeal souls, and this possibility is defeated in a conceptual manner, then it seems that physicalism should be accepted as a conceptually necessary theory, which could not be grounded on the empirical findings of science. But this is completely contrary to the fundamental principles of any theory which purports to be physicalist.

Against the current unanimous conviction, I think that the contingency of physicalism need not depend on the feasibility of the Cartesian approach. There are different ways in which the physicalist theory could

See also Chalmers, 1996: 38-9, Jackson, 1994: 28, 2007: 192-4, Lewis, 1983: 362, Shoemaker, 2010: 125-6, Stalnaker, 2004: 395. 
be empirically false. To take an extreme example, perhaps we could consider (if it is actually conceivable) the possibility of an entity that has no causal or nomological dynamics, which could not qualify as physical. If this is so, then we must say that there are at least possible entities that do not fall within the concept of the physical. We might also remember that it is almost obvious that a panpsychist world in which electrons, quarks, and superstrings are endowed with intelligence and/or consciousness, cannot qualify as a physical world; it seems that the very concept of physical entity excludes this possibility. ${ }^{8}$ Also, as we have suggested, a world with some non-mathematically expressible phenomena does not seem to qualify as a physicalist world. If so, the idea that physicalism is contingent does not require the controversial, plausibly incoherent possibility of a Cartesian mind.

\section{What is to be physical?}

We have seen that physicalism is both an a posteriori and contingent theory, in the sense that it should respond to the empirical results of the sciences. But we have also seen that this theory must respond to some conceptual conditions presupposed by the very notions of physical science and physical entity, conditions which would allow us to assess whether some eventual final and complete science constitutes or not a physical science.

We know that most philosophers consider that physicalism should be understood as the idea that the physical characteristics of our world constitutively determine all its empirical characteristics. Jackson, for instance, argues that physicalism about phenomenal consciousness (mental states that have qualitative properties or qualia) affirms that the properties required for the constitution and characterization of the non-sentient or non-conscious items of our world, such as water molecules, force fields, cells, and nerve fibers, "are enough for all of our world including, for example, the humans and the cats" (Jackson, 2007: 193). According to this way of understanding physicalism, physical, chemical, biological, and neurological properties are both ontologically and epistemologically sufficient for the constitution and explanation of animal and human consciousness. In this case, physical simply means "non-sentient". But here lies one major issue: why and in what sense the chemical, biological, and neurological entities, such as water molecules, cells, and nerve fibers count as physical?

8 See, for instance, Wilson, 2005: 428, Montero, 2006: 182, Stoljar, 2010: 88. 
Accepting that chemical and biological elements qualify as physical in their own right is a ubiquitous fact within both the philosophical and the scientific domains. This is why most physical reductionist theories regarding not only consciousness but mind in general, not to mention moral, economic, political, and related phenomena, are articulated in terms of brain and nerve activities that the persons or bodies have. Some philosophers address the issue without giving it real importance. About the characterization of what counts as a physical property, in another of his texts, Jackson tells us:

Roughly, I will mean what is typically meant: the kinds of properties that figure in, or are explicitly definable in terms of, those that figure in physics, chemistry, biology, and neuroscience. This rough characterisation leaves it open why those sciences, rather than say psychology or politics, are chosen to settle the favoured class, and it says nothing about how committed this approach is to those sciences being roughly right in the kinds of properties they need for their own internal purposes. Nevertheless, I think that the rough characterisation will do for our purposes here. As far as I can see, nothing in what follows turns on the answers to these two controversial matters. What is important here is that there is a favoured list, not how a property or relation gets to be on that favoured list. (Jackson, 1994: 26)

This philosopher seems to suggest that it is not relevant to know the criterion by which we determine that certain elements, such as chemical and biological, count as essentially physical. It seems that what is relevant to physicalism is to build a list of items and categories that must be understood as constituting an undeniable part of the physical. From that list, physicalists must build their version of reality. ${ }^{9}$

But this approach is unsatisfactory. Recall that physicalism is an a posteriori thesis affirming that its empirical foundation must be given by a recognizable descendant of the current physical science. But in order to assess whether some eventual science constitutes or not a physical science, it is not enough to have a list of items currently considered as paradigmatically physical; a list of the form: electrons, atoms, water molecules, cells, nerve fibers, etc. In the same sense, it is not enough to argue that such a final science will rely solely on categories of microphysics, chemistry, biology, and neurology. We do not know if neurology will require appealing to psychological, sociological, or aesthetic properties to account for what happens in the brains of people. In this case, would psychological, sociological, or aesthetic properties count as physical in their own right? Or

$9 \operatorname{Kim}(1993: 340)$ seems to affirm the same claim. 
rather would they falsify physicalism? What we need is a more or less stable criterion about what we understand under the concept of the physical.

\section{Microphysical supervenience as the criterion for the physical}

Theorists of recent decades have tried to solve this problem by appealing to the understanding that we can acquire from notions such as dependence, determination, and supervenience. The idea is that a theory that deserves the name of physicalism should assert that there are some privileged items from which everything else is constituted, understood, and explained. If we are physicalists about the mind, for example, we cannot simply say that the mind is one of these physical items, but we have to show how it is constituted and understandable from the entities we always have considered as physical, or from those we can identify as physical irrespective of their mental character.

From this idea is that the theory that has been predominant in recent decades takes its articulation: chemical, biological, and neurophysiological entities qualify as physical because they supervene on - are logically ${ }^{10}$ determined by - their basic physical constituents, that is, their ultimate microphysical elements. We can call this position, as Pettit (1994) does, microphysicalism. ${ }^{11}$

Although the microphysicalist approach is the most accepted by philosophers and scientists, it entails very deep empirical and conceptual difficulties. One of the central problems of this approach is that there is strong empirical evidence that seems to show its falsity: there are examples of systems within the scope of physics itself which seem to have holistic properties that do not logically supervene on the properties and relations of their most basic constituents. This means that from an empirical standpoint there would be at least some physical systems with physical properties that are not completely determined by the properties and relations of their physical constituents; properties which, in this sense, we can call essentially macrophysical. In this case, strict microphysicalism would become a falsified theory.

One of the most recurrent examples that seem to show the falsity of the microphysical supervenience is the phenomenon of the quantum

\footnotetext{
10 In every logical or metaphysical possible world.

11 Some of the theorists who understand physicalism in this way are Pettit, 1994, Chalmers, 1996, Kim, 2005, McLaughlin, 2007, and Shoemaker, 2007.
} 
states of entanglement. ${ }^{12}$ An entangled quantum state is a state of a system of subatomic entities (such as electrons) characterized by having a state vector (or wave function) that is not factorizable in terms of the state vectors of its components; that is, a quantum state which contains additional information, not reducible to its components' information. There is strong empirical evidence that supports the objective existence of this kind of physical phenomenon, ${ }^{13}$ that violates the microphysical supervenience thesis in the sense of having a holistic property that is neither determined by nor explainable from the pure properties and relations of their physical components. Moreover, this quantum holistic phenomenon seems to be a ubiquitous fact of our world: it is not only present in physical systems composed of elementary particles but, as Papineau says, it is also "present in systems comprising basic physical persisting objects, like atoms and molecules." (2008: 146)

But it seems that this case is not isolated; it seems that within the scope of the physical science we find numerous examples of holistic properties which do not metaphysically supervene on the properties of their most basic constituents; or, at least, this is what the scientific contemporary fact of not being properly explained in terms of their most basic constituents suggests. This is the thought of two of the important scientific voices who reject the widespread microphysicalist assumption, A.J. Leggett, Nobel laureate in physics, and Roald Hoffmann, Nobel laureate in chemistry: ${ }^{14}$

[T] here are also a number of cases, particularly in the traditional areas of the physics of gases and crystalline solids, in which a model which treats the behavior of the whole as essentially just the sum of that of its parts (atoms or electrons) has been quite successful. [...] But these cases, despite the fact that they totally dominate the presentation of the subject in most elementary textbooks, are actually the exception rather than the rule. In virtually all the frontier areas of modern condensed-matter physics, the relationship between our understanding of the behavior of matter at the microscopic level of single atoms and electrons, and at the macroscopic level of (say) liquids and solids, is actually a good deal more complicated than this. [...] I would claim that the most important advances in this area come about by the emergence of qualitatively new concepts at the intermediate or macroscopic levels - concepts which, one hopes, will be com-

12 See, for example, Maudlin, 1998, Silberstein \& McGeever, 1999, Papineau, 2008.

13 See, for instance, Aspect, Grangier \& Roger, 1981.

14 In this non-reductive physicalist direction see also the work of the Nobel laureates in physics, P.W. Anderson (1972) and Murray Gell-Mann (1994: especially pp. 111-3). 
patible with one's information about the microscopic constituents, but which are in no sense logically dependent on it. (Leggett, 1987: 113-5)

Meanwhile, on the relationship between physics and chemistry, Hoffmann says:

My stronger claim is that most concepts in chemistry that have proven productive in the design of new experiments are not reducible to physics. By this I mean that they cannot be redefined adequately using only the language of physics. To be specific, I'm thinking of aromaticity, the acidbase concept, the idea of a functional group, a substituent effect, and that of a chromophore. And let us not forget the chemical bond. (Hoffmann, 2007: 329)

This leads us to consider that from a scientific point of view it is highly plausible that within the physical and chemical scopes of matter we come to find phenomena that cannot be understood under the criteria of microphysical logical supervenience. ${ }^{15}$ But there is also evidence for the idea that the failure of metaphysical supervenience goes beyond the physical and chemical scopes. For instance, there is an empirically based growing agreement on the idea that biological properties cannot be properly and completely understood and explained from their underlying physical and chemical processes. ${ }^{16}$

\section{Consequences for determining the concept of the physical}

These empirical results lead us to a direct and crucial conclusion for our current research: it is not the relation of microphysical supervenience which plays the role of being the criterion for considering the holistic physical systems, much less the chemical and biological systems, as physical phenomena in their own right. In this sense, if the microphysicalist theory was the only proposal for understanding our concept of the physical, we would have no way to assert, as obviously we do, that the physical holistic levels, along with the chemical and biological, count as paradigmatic physical realms.

Now, I have to emphasize the following point: the crucial fact is not that the failure of microphysical supervenience takes us to the conclusion

\footnotetext{
15 On the empirically plausible failure of microphysical supervenience within the (non-quantum) physical and chemical scopes see also, for example, Primas, 1998, Sklar, 1999, and Kistler, 2006.

16 See, for example, Wimsatt, 2007, Dupré 2012, and Davies 2012.
} 
that it is not the relation of microphysical supervenience which plays the role of being the criterion for evaluating entities as physical; although it does. The crucial fact is that the simple possibility of the failure of supervenience shows us that the macrophysical scopes are not understood as physical on the basis of their supervenience on their microphysical elements. And this is so, even whether they were actually supervenient.

With regard to the philosophical implications of the empirical failure of the microphysical theories, authors like Barbara Montero and David Papineau develop similar conclusions to the outlined here. Montero tells us:

[I]magine that duplicating fundamental physics could give us a world with, say, just quarks, leptons, their antiparticles, and such like, but no chemical bonds, no molecules, no cells, no organisms. If our world were like this, chemical properties, among others, would fail to supervene on fundamental physics. Must this be a world in which physicalism is false? Or to narrow the question down, must we understand the chemical bonds (and the properties thereof) in this world as nonphysical? There seems to be no reason to think that we must. Yet if this is correct, physicalism can be true even if chemical, biological, psychological, and other such properties fail to supervene on the entities, properties, laws, and relations of physics. (Montero, 2013: 101)

In the same sense Papineau affirms:

The properties of atoms and molecules may be irredeemably holist because of quantum non-locality, but these properties are surely still physical. We don't want to say that the total spin of a number of electrons doesn't count as 'physical' just because it isn't determined by the local properties of the individual electrons. (Papineau, 2008: 146)

Now I want to insist in the kind of conceptual problems that the philosopher who tries to understand the physicalist approach based on a supervenience theory should face. As we will see, the problem of microphysicalism is not based on its assumption of certain priority of the microscopic, but on its idea that we can (maybe have to) understand the physicalist position through a theory of supervenience. The conclusion will be that the theory of microphysical supervenience is neither necessary, since we have a concept of the physical regardless of its truth or falsity, nor sufficient, since assuming its truth we could derive unacceptable conceptual consequences.

Many contemporary philosophers have relied so much on the criterion of microphysical supervenience that they have assumed the conceptual and metaphysical possibility that mental phenomena, as well as shopping centers and wars (Jackson, 2003: 85), botanical and automotive proper- 
ties (Shoemaker, 2010: 125-6), biological properties of reproduction and evolution (Chalmers, 1996: 39), and even entities such as water and heat (Block \& Stalnaker, 1999: 18, 29), can be instantiated in, and be realized by "immaterial mechanisms." But I think that this idea is simply incoherent.

These authors come to accept what I consider incoherent because they assume the combination of the following two ideas: (i) that "essentially physical' really means 'microphysical;' and (ii) that a physical world is that which is completely determined, that is, which metaphysically supervenes on, the microphysical facts. Since shopping centers, wars, automotive and botanical properties, the biological properties of reproduction and evolution, water, heat, cells, neurons, etc., are not microphysical phenomena, then, under their criterion, these are not physical phenomena in their own right, but only in a derivative way, only if they come to supervene on microphysical facts. Two important consequences follow: first, that given that the macroscopic properties are not essentially physical, they could be instantiated in non-material mechanisms; and, second, that the contingency of physicalism should be understood as implying the possibility that the macroscopic features of our world can be realized by immaterial mechanisms.

As I pointed out, contemporary physicalists make a mistake when they assume that the contingency of their thesis should depend on the possibility of a Cartesian mind which can be instantiated in immaterial mechanisms. Moreover, I think the idea of an immaterial mind does not make sense; but much less the idea that reproduction, evolution, dogs, trees, rocks, heat, and water can be instantiated in a non-physical stuff! That there can be, in the words of Block and Stalnaker (1999: 18, 28), ghost heat and water, immaterial heat and water.

The mistake of these authors is based on the fact that their two main assumptions (that 'essentially physical' means 'microphysical,' and that a physical world should be one which metaphysically supervenes on the microphysical) are deeply problematic; in fact, deeply problematic in a conceptual way. We have seen that current physics, not to mention other sciences, considers that there is strong evidence of holistic physical phenomena, which do not supervene on their microphysical constituents. Plausibly holistic phenomena as entangled quantum systems, relativistic gravitational fields, chemical bonds, and neural firings are considered clearly physical entities by the branches of the physical sciences that study them. This makes it clear that physical does not mean microphysical. Precisely because physical does not mean microphysical, we can say that water, rocks, heat, cells, and nerve fibers can be, and indeed, are considered paradigmatic cases of physical entities. 
I have spent most of the paper trying to show that the most accepted formulation of physicalism, the microphysical supervenience theory, has deep empirical and conceptual deficiencies. If this is correct, we have all the reasons for constructing a non-reductive concept of physicalism that describes a world wherein some of its fundamental phenomena can be essentially macrophysical (we can say, emergent ${ }^{17}$ ), i.e., physical phenomena that do not supervene on, cannot be reduced to, nor understood purely in terms of the properties of their microphysical components. But this account must be left for another occasion. ${ }^{18}$

\section{REFERENCES}

Anderson, P.W. (1972), "More is different", Science No. 177, reprinted in M. Bedau \& P. Humphreys (eds., 2008), Emergence: Contemporary Readings in Philosophy and Science. Massachusetts Institute of Technology.

Aspect, A.; Grangier, P. \& Roger, G. (1981), "Experimental Tests of Realistic Local Theories via Bell's Theorem," Phys. Rev. Lett., 47: 460.

Barnes, Elizabeth (2012), "Emergence and Fundamentality," Mind, Vol. 121, 484.

Bennett, Karen (2008), "Exclusion Again", in Jesper Kallestrup and Jakob Hohwy (eds.), Being Reduced: New Essays on Reduction, Explanation, and Causation, New York: Oxford University Press.

Block, N. \& Stalnaker, R. (1999), "Conceptual analysis, dualism and the explanatory gap", The Philosophical Review 108: 1-46.

Chalmers, David (1996), The Conscious Mind, Oxford: Oxford University Press.

Crane, Tim \& Mellor, D. H. (1990), “There is No Question of Physicalism”, Mind, New Series, Vol. 99, No. 394, Oxford University Press.

Davies, Paul (2012), "The epigenome and top-down causation", Interface Focus 2: $42-48$.

d'Holbach, Paul-Henri ([1770] 1970), System of Nature, translated by H.D. Robinson, New York: Burt Franklin.

Dupré, John (2012), Processes of Life. Essays in the philosophy of biology, New York: Oxford University Press.

Gell-Mann, Murray (1994), The Quark and the Jaguar: Adventures in the Simple and the Complex, New York: W. H. Freeman and Company.

Hellman, G. (1985), "Determination and logical truth", Journal of Philosophy, 82/11: 607-16.

17 On the internal relation between macrophysicalism and emergentism see Barnes, 2012, and Morales, 2015.

18 See Morales, 2015. 
Hoffmann, Roald (2007), "What might philosophy of science look like if chemists built it?" Synthese 155: 321-336.

Jackson, Frank (1994), “Armchair Metaphysics”, in M. Michael and J. Hawthorne (eds.), Philosophy in Mind, Amsterdam: Kluwer.

- (1998), From Metaphysics to Ethics, Oxford University Press.

- (2003), "From $\mathrm{H}_{2} \mathrm{O}$ to water. The relevance to a priori passage", in Hallvard Lillehammer and Gonzalo Rodriguez-Pereyra (eds.), Real Metaphysics. Essays in honour of D. H. Mellor, New York: Routledge.

- (2007), "A Priori Physicalism", in Contemporary Debates in Brian P. McLaughlin and Jonathan Cohen (eds.), Philosophy of Mind.

Kim, Jaegwon (1993), Supervenience and mind. Selected philosophical essays, New York: Cambridge University Press.

- (2005), Physicalism, Or Something Near Enough, New Jersey: Princeton University Press.

- (2011), Philosophy of Mind, Third Edition, Boulder: Westview Press.

Kistler, Max (2006), "Reduction and emergence in the physical sciences: Reply to Rueger", Synthese, 151: 347-354.

Leggett, A.J. (1987), The Problems of Physics, New York: Oxford.

Lewis, David (1983), "New Work for a Theory of Universals", Australasian Journal of Philosophy, Vol. 61, No. 4.

Maudlin, T. (1998), "Part and whole in quantum mechanics", in E. Castellani (ed.), Interpreting Bodies: Classical and Quantum Objects in Modern Physics, Princeton, NJ: Princeton University Press.

McLaughlin, Brian (2007), "On the Limits of A Priori Physicalism", in Brian P. McLaughlin and Jonathan Cohen (eds.), Contemporary Debates in Philosophy of Mind.

— \& Bennett, Karen (2014), "Supervenience", in The Stanford Encyclopedia of Philosophy (Spring 2014 Edition), Edward N. Zalta (ed.), URL $=<$ http:// plato.stanford.edu/archives/spr2014/entries/supervenience/>.

Mettrie, J.O. de la, (1748), Man a Machine, tr. by G. C. Bussey, La Salle, IL: Open Court Press, 1912.

Montero, Barbara (2006), "Physicalism in an Infinitely Decomposable World", Erkenntnis, Vol. 64, No. 2: 177-191.

- (2013), "Must Physicalism Imply the Supervenience of the Mental on the Physical?", The Journal of Philosophy, 110 (2): 93-110.

Morales (2015), "Nonreductive physicalism: understanding our metaphysical paradigm", Pulse: A Graduate Journal of History, Sociology \& Philosophy of Science, Issue 3: 27-43.

Papineau, David (2008), "Must a Physicalist be a Microphysicalist?", in Jesper Kallestrup and Jakob Hohwy (eds.), Being Reduced: New Essays on Reduction, Explanation, and Causation, New York: Oxford University Press. 
Pettit, Philip (1994), "Microphysicalism without contingent macro-micro laws", Analysis 54: 253-57.

Primas, Hans (1998), "Emergence in the exact sciences", Acta Polytechnica Scandinavica, 91: 83-98.

Shoemaker, Sydney (2007), Physical realization, New York: Oxford University Press.

— (2010), "Reply to my critics," in Philosophical Studies: An International Journal for Philosophy in the Analytic Tradition, Vol. 148, No. 1.

Silberstein, Michael \& McGeever, John (1999), "In Search for Ontological Emergence", Philosophical Quarterly, 49: 182-200.

Sklar, Lawrence (1999), "The Reduction(?) of Thermodynamics to Statistical Mechanics", Philosophical Studies, Vol. 95, No. 1/2: 187-202.

Stalnaker, Robert (2004), "What is it Like to be a Zombie," in Tamar Gendler and John Hawthorne (eds.), Conceivability and Possibility.

Stoljar, Daniel (2010), Physicalism, New York: Routledge.

Wilson, Jessica (2005), "Supervenience-based Formulations of Physicalism", Noûs, 39:3, 426-459. Blackwell Publishing.

Wimsatt, William (2007), Re-Engineering Philosophy for Limited Beings. Piecewise approximations to reality, Cambridge: Harvard University Press. 


\begin{abstract}
In this paper I focus on the analysis of the concept of the physical and its implications for the formulation of physicalism. Most of the paper is "negative," insofar as it intends to show why the most accepted formulation of physicalism, the theory of the supervenience or complete determination of the empirical phenomena by the microphysical characteristics, has deep empirical and conceptual deficiencies: on one hand, it seems to be incompatible with the results of different sciences and, on the other, it allows us to understand neither the scientific nor the daily use of the notion of the physical. If this is the case, then we have strong reasons for constructing a non-reductive concept of physicalism that describes a world wherein some of its fundamental phenomena can be essentially macrophysical, i.e., physical phenomena which cannot be reduced to, nor understood purely in terms of the properties of their microphysical components.
\end{abstract}

Key-words: The physical - supervenience - microphysicalism - special sciences - reduction

\title{
RESUMEN
}

En este artículo analizo el concepto de lo físico y sus implicaciones para la formulación del fisicalismo. La mayor parte del artículo es "negativo", en tanto que intenta mostrar porqué la formulación más aceptada del fisicalismo, la teoría de la superveniencia o completa determinación de los fenómenos empíricos por parte de las características microfísicas, tiene deficiencias profundas tanto empíricas como conceptuales: de un lado, parece ser incompatible con los resultados de las diferentes ciencias y, del otro, no nos permite comprender ni el uso científico ni cotidiano de la noción de lo físico. Si este es el caso, entonces tenemos razones poderosas para construir un concepto no-reductivo del fisicalismo que describa un mundo en el cual algunos de sus fenómenos fundamentales pueden ser esencialmente macrofísicos, esto es, fenómenos físicos que no pueden ser reducidos ni entendidos puramente en términos de las propiedades de sus componentes microfísicos.

Palabras clave: Lo físico - superveniencia - microfisicalismo - ciencias especiales - reducción 